\title{
Study on Performance of Co-W/SiC Composite Coatings Electrodeposited on Copper
}

\author{
KangNing Zhao, Guoying Wei ${ }^{*}$, Hongliang Ge, Yundan $Y u^{*}$ \\ College of Materials and Chemistry, China Jiliang University, Hangzhou, China \\ *E-mail: yuyundan@sina.com
}

doi: $10.20964 / 2021.02 .07$

Received: 28 September 2020 / Accepted: 6 November 2020 / Published: 31 December 2020

In this paper, $\mathrm{CoW} / \mathrm{SiC}$ composite coatings were electrodeposited from plating bath with various nano $\mathrm{SiC}$ concentrations. The effect of $\mathrm{SiC}$ concentrations on deposition rate, hardness, corrosion resistance and surface morphology of $\mathrm{CoW} / \mathrm{SiC}$ coatings were studied. It was found that the appropriate concentration of $\mathrm{SiC}$ was beneficial to increase the deposition rate, refine the surface particles and improve hardness of the composite coatings. However, when the SiC concentration was greater than 12 $\mathrm{gL}^{-1}$, the agglomeration effect of the suspended $\mathrm{SiC}$ particles greatly reduced the deposition rate and mechanical properties of the $\mathrm{CoW} / \mathrm{SiC}$ composite coatings. The coating prepared at the concentration of $8 \mathrm{gL}^{-1} \mathrm{SiC}$ possessed the best hardness and corrosion resistance.

Keywords: CoW/SiC composite coatings; plating technology; nano SiC; Corrosion resistance;

\section{$\underline{\text { FULL TEXT }}$}

(C) 2021 The Authors. Published by ESG (www.electrochemsci.org). This article is an open access article distributed under the terms and conditions of the Creative Commons Attribution license (http://creativecommons.org/licenses/by/4.0/). 